\begin{tabular}{|l|l|l|}
\hline \multicolumn{2}{|c|}{ PublisherInfo } \\
\hline \hline PublisherName & $:$ & BioMed Central \\
\hline \hline PublisherLocation & $:$ & London \\
\hline \hline PublisherImprintName & $:$ & BioMed Central \\
\hline \hline
\end{tabular}

\title{
Coronary event risk needs to be quantified before advising aspirin for primary prevention
}

\begin{tabular}{|l|l|l||}
\hline \multicolumn{2}{|c||}{ ArticleInfo } \\
\hline \hline ArticleID & $:$ & 35 \\
\hline \hline ArticleDOI & $:$ & $10.1186 /$ cvm-2001-72100 \\
\hline \hline ArticleCitationID & $:$ & 72100 \\
\hline \hline ArticleSequenceNumber & $:$ & 14 \\
\hline \hline ArticleCategory & $:$ & Paper Report \\
\hline \hline ArticleFirstPage & $:$ & 1 \\
\hline \hline ArticleLastPage & $:$ & 3 \\
\hline \hline & & RegistrationDate : 2001-10-18 \\
ArticleHistory & $:$ & Received $\quad: 2001-3-7$ \\
& $:$ & OnlineDate $\quad 2001-10-18$ \\
\hline \hline ArticleCopyright & $:$ & Biomed Central Ltd2001 \\
\hline \hline
\end{tabular}




\begin{tabular}{|l|l|l|}
\hline ArticleGrants & $:$ & \\
\hline \hline ArticleContext & $:$ & 1306322 \\
\hline
\end{tabular}

Joanna Lyford, Aff1

Corresponding Affiliation: Aff1

Aff1 MedWire, UK

Keywords

Aspirin, coronary heart disease, primary prevention, meta-analysis

\section{Context}

The benefit of aspirin in the secondary prevention of coronary heart disease greatly outweighs the possible damage from hemorrhage. In primary prevention the situation is less clear cut. This study aims to discover the thresholds of cardiovascular and coronary risk at which benefits of treatment are sufficiently great and potential costs small enough to justify the use of aspirin in primary prevention.

\section{Significant findings}

Aspirin significantly reduced all cardiovascular events by $15 \%$ (95\% confidence interval [CI] $6 \%$ to $22 \%$ ) and myocardial infarctions (MIs) by $30 \%$ (95\% CI $21 \%$ to $38 \%$ ). It also significantly reduced all deaths by $6 \%$ ( $95 \%$ CI $-4 \%$ to $15 \%$ ). However, aspirin also nonsignificantly increased strokes by $6 \%$ ( $95 \%$ CI $-24 \%$ to $9 \%$ ) and significantly increased bleeding complications by $69 \%$ (95\% CI $38 \%$ to $107 \%$ ). The increased risk of major bleeding balanced the reduction in cardiovascular events when cardiovascular event risk was $0.22 \%$ per year. At a coronary heart disease event risk of $1.5 \%$ per year, aspirin appeared to give an acceptable outcome, with one MI prevented and without any important bleeding for every 77 patients treated. At a lower coronary heart disease risk level of $0.5 \%$ per year, however, aspirin is unattractive. At this level of risk, the chance of having a significant bleed was higher than that of preventing MI. Harm from aspirin is unlikely to outweigh benefit provided the cardiovascular event risk is $30.8 \%$ per year, equivalent to a coronary risk of $0.6 \%$ per year. 


\section{Comments}

Aspirin cannot be prescribed safely for primary prevention without formal estimation of coronary disease event risk in the individual. "Intuitive assessment of coronary heart disease risk and reliance on single risk factors, such as lipids or blood pressure, are highly inaccurate. Simple counting of coronary heart disease risk factors improves accuracy, but it still identifies people at very low risk and fails to identify all high risk people for treatment." Aspirin treatment should be guided by formal estimation of coronary heart disease risk using epidemiological studies, such as the Framingham approach.

\section{Methods}

Meta-analysis of four randomized trials of aspirin for primary prevention in order to quantify benefit and harm from aspirin treatment at different levels of coronary heart disease (CHD) risk. The trials included the US Physicians Health Study, the UK Doctors study, the Thrombosis Prevention Trial, and the Hypertension Optimal Treatment (HOT) study.

\section{Additional information}

In a related editorial the authors are congratulated on their approach:

Lowe GDO: Who should take asprin for primary prophylaxis of coronary heart disease? Heart 2001, 85:245-246.

\section{References}

1. Sanmuganathan PS, Ghahramani P, Jackson PR, Wallis EJ, Ramsay LE: Aspirin for primary prevention of coronary heart disease: safety and absolute benefit related to coronary risk derived from meta-analysis of randomised trials. Heart. 2001, 85: 265-271. 